February 2000 - NREL/CP-500-27497

\title{
Comprehensive Testing of Nedwind 12-Meter Wind Turbine Blades at NREL
}

S. Larwood and W. Musial

Presented at the $19^{\text {th }}$ American Society of Mechanical Engineers (ASME) Wind Energy Symposium Reno, Nevada January 10-13, 2000

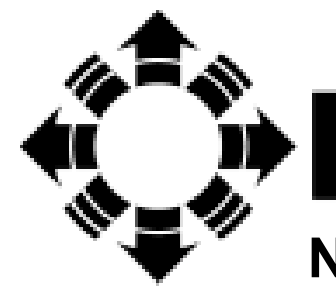

\section{NPE}

National Renewable Energy Laboratory

1617 Cole Boulevard

Golden, Colorado 80401-3393

NREL is a U.S. Department of Energy Laboratory

Operated by Midwest Research Institute $\bullet$ Battelle $\bullet$ Bechtel

Contract No. DE-AC36-99-G010337 


\section{NOTICE}

The submitted manuscript has been offered by an employee of the Midwest Research Institute (MRI), a contractor of the US Government under Contract No. DE-AC36-99G010337. Accordingly, the US Government and MRI retain a nonexclusive royalty-free license to publish or reproduce the published form of this contribution, or allow others to do so, for US Government purposes.

This report was prepared as an account of work sponsored by an agency of the United States government. Neither the United States government nor any agency thereof, nor any of their employees, makes any warranty, express or implied, or assumes any legal liability or responsibility for the accuracy, completeness, or usefulness of any information, apparatus, product, or process disclosed, or represents that its use would not infringe privately owned rights. Reference herein to any specific commercial product, process, or service by trade name, trademark, manufacturer, or otherwise does not necessarily constitute or imply its endorsement, recommendation, or favoring by the United States government or any agency thereof. The views and opinions of authors expressed herein do not necessarily state or reflect those of the United States government or any agency thereof.

Available electronically at http://www.doe.gov/bridge

Available for a processing fee to U.S. Department of Energy and its contractors, in paper, from:

U.S. Department of Energy

Office of Scientific and Technical Information

P.O. Box 62

Oak Ridge, TN 37831-0062

phone: 865.576 .8401

fax: 865.576.5728

email: reports@adonis.osti.gov

Available for sale to the public, in paper, from:

U.S. Department of Commerce

National Technical Information Service

5285 Port Royal Road

Springfield, VA 22161

phone: 800.553 .6847

fax: 703.605.6900

email: orders@ntis.fedworld.gov

online ordering: http://www.ntis.gov/ordering.htm

Printed on paper containing at least $50 \%$ wastepaper, including $20 \%$ postconsumer waste 


\title{
COMPREHENSIVE TESTING OF NEDWIND 12-METER WIND TURBINE BLADES AT NREL
}

\author{
Scott Larwood and Walt Musial \\ National Renewable Energy Laboratory \\ Golden, Colorado
}

\begin{abstract}
This paper describes the structural testing of two NedWind 25, 12-m blades at the National Renewable Energy Laboratory (NREL). The tests were conducted under the Standards, Measurement and Testing (SMT) Program in conjunction with tests conducted by four European laboratories to develop a common database of blade testing methods. All of the laboratories tested duplicate copies of blades taken from series production. Blade properties, including weight, center of gravity, natural frequencies, and damping were determined. Static load tests were performed at $110 \%$ of the extreme design load for strain verification. NREL performed single-axis and two-axis fatigue tests using "businessas-usual" testing practices. The single-axis test combined equivalent life loading for the edge and flap spectra into a single resultant load. The two-axis test applied the edge and flap components independently at a phase angle of $90^{\circ}$. Damage areas were observed at (1) the trailing edge, which cracked near the maximum chord; (2) between the steel root collar and the composite, where circumferential cracking was noted; and (3) along the top of the spar between the 2500-mm and 4200-mm stations, where a notable increase in acoustic emissions was detected. NREL observed that the onset of visible damage occurred earlier in the single-axis test.
\end{abstract}

\section{INTRODUCTION}

The wind turbine industry has performed structural testing of wind turbine blades for many years. According to surveys conducted in Europe, most wind turbine and blade manufacturers now consider blade testing a requirement. Although the International Electrotechnical Commission (IEC) initiated standardization of wind turbine blade testing in 1994, a prescriptive standard that is internationally accepted does not yet exist, because the area of structural blade testing is not yet mature. In spite of this, wind turbine certification bodies are moving towards full-scale static and fatigue testing of wind turbine blades for design verification. In 1998, the IEC Technical Committee 88-

This material is declared a work of the U.S. Government and is not subject to copyright protection in the United States.
Wind Turbine Systems (TC 88) approved draft text IEC 61400-22 that will require both ultimate static testing and fatigue testing of wind turbine blades for type certification if it is approved by the national committees. $^{1}$

The SMT Program, initiated in 1996 in Europe, helps blade testing laboratories harmonize their testing methods and come closer to a standard set of blade testing procedures. Each participating laboratory benefits by having its procedures evaluated internationally, while they observe firsthand, the methods used by others.

Three European member countries and the United States participated in this project, represented by five laboratories including RIS $\varnothing$ (Denmark), CRES (Greece), Delft (Netherlands), ECN (Netherlands) and NREL (U.S.). NREL was an invited member of this project and its participation was voluntary. However, NREL completed all the requirements of the project and participated as an equal partner using its own funding.

The SMT Program objectives were:

- To make a reference database for different test methods, test techniques, and test results of static and fatigue testing of wind turbine blades being used by different laboratories.

- To gain a greater collective understanding of the technical challenges of blade testing and to bring the international laboratories closer to a unified approach. Through this program, results from different laboratories may be shared and widely accepted.

NREL has been involved in blade testing since 1990 and has tested over 75 wind turbine blades. Most of these tests were funded through the U.S. Department of Energy's (DOE's) turbine development projects. Because this work is proprietary in nature and is not usually available to the public, its development and dissemination of NREL testing methods have been inhibited. The SMT program gave NREL an opportunity to share its test results and methods amongst the project laboratories and with the wind industry at large. 


\section{SMT PROGRAM DESCRIPTION}

SMT Program laboratories began by selecting a commercial blade model with good design records that could be released to the participating laboratories. They selected blades from a series production and randomly assigned a blade to each laboratory. CRES and NREL agreed to test two blades while the other laboratories performed their tests on one blade. The blades were weighed and identified at ECN before they were sent to the test laboratories. Each blade was also marked to identify the position of common strain gages. The laboratories were free to add additional measurement locations at their discretion.

The SMT project laboratories agreed upon common prescribed static tests to determine blade properties. Each laboratory was then required to perform a fatigue test on the blade. The laboratories were to independently determine fatigue test loads based on the design data, and then perform the tests using their "business as usual" practices. When possible, the laboratories agreed to follow the principles in IEC 61400-23 to reduce variability in the methods. ${ }^{2}$ NREL used the test load factors described in the draft IEC 61400-23 document to determine its test loads.

\section{TEST BLADE DESCRIPTION}

The NedWind 25 blade was chosen as the program test article. Rotorline (now part of LM Glasfiber) in the Netherlands manufactured the blade, and a production surplus was available for testing. NREL chose to purchase and test two blades, because of the low incremental shipping costs for an extra blade and to provide a spare in case the first blade failed early in testing. In addition, the second blade allowed NREL to compare two different fatigue-testing methods: singleaxis combined loading and two-axis loading.

The NedWind 25 is a $250-\mathrm{kW}$, upwind, pitch regulated, three-bladed machine. The turbines, manufactured in 1992, are operated in the Netherlands and Curaçao (Figure 1). The blades are 12-meters long and are constructed of glass fiber reinforced polyester. Each blade has a single spar running from $17 \%-83 \%$ of blade span at $40 \%$ chord (Figure 2) and is constructed with high strength laminates at the root and at the panels surrounding the blade spar. Lower strength material is used on the leading and trailing edges. The blade hub attachment is a steel flange that clamps with radial bolts around the blade root (Figure 3).
Rotorline and NedWind provided blade structural and design load information to the project laboratories. This documentation included a complete set of 100 design load cases at ten spanwise blade stations. For each load case, the number of cycles was given with three principal loads: flap moment, edge moment, and axial forces. These loads were given for both the mean and the alternating component. The design documents also included a complete description of the design, including design load, material, and the stress concentration factors used for the static and fatigue analysis. The fatigue analysis also gave theoretical damage values at numerous points over the blade planform.

The span locations referred to in this paper are at a distance or percentage distance from the center of rotation. The mating flange surface of the blade is at $0.65 \mathrm{~m}$.

\section{BLADE PROPERTY TESTS}

The laboratories agreed to perform a set of tests to determine the as-built properties of the blade. The tests included static loading of the blade to a prescribed proof load that was to be low enough to avoid damaging the blade for fatigue testing. The uncertainties reported are within a $95 \%$ confidence limit.

\section{Blade Weight and Center of Gravity}

The weight and center of gravity (CG) of the blades were measured at the Rotorline factory after balancing. The Rotorline and NREL measurements were made with load cells at the flange and at 9.5 meters from the blade flange.

Table 1- Blade Weight and CG

\begin{tabular}{ccc}
\hline $\begin{array}{c}\text { Blade } \\
\text { Number }\end{array}$ & $\begin{array}{c}\text { Rotorline } \\
\text { Weight/CG } \\
(\mathrm{kg} / \mathrm{meters})\end{array}$ & $\begin{array}{c}\text { NREL } \\
\text { Weight/CG } \\
(\mathrm{kg} / \mathrm{meters})\end{array}$ \\
\hline 66 & $759.36 / 2.99$ & $757 / 3.07$ \\
67 & $759.28 / 2.99$ & $757 / 3.07$ \\
\hline
\end{tabular}

The uncertainties in the NREL values are $\pm 6 \mathrm{~kg}$ and \pm 0.02 meters. Note that NREL weighed the blades after the fatigue tests and the blade weight and CG include stain gage instrumentation and lead wires. 


\section{$\underline{\text { Eigenfrequencies }}$}

All of the laboratories were required to determine the first and second flap and edge blade frequencies and the first torsional frequency. NREL conducted a modal survey on one blade using impact measurements to determine the mode shapes. With this information, driving point measurements were made with the second blade to determine frequencies, using the assumption that the mode shapes would be virtually the same. The torsional frequency was determined by measuring the cross product of the accelerations at the leading and trailing edge of the blade chord at $83 \%$ span.

Table 2 - Eigenfrequency Results

\begin{tabular}{lcc}
\hline Mode & $\begin{array}{c}\text { Blade \#66 } \\
\text { Frequency (Hz) }\end{array}$ & $\begin{array}{c}\text { Blade \#67 } \\
\text { Frequency }(\mathrm{Hz})\end{array}$ \\
\hline First Flap & 2.500 & 2.500 \\
First Edge & 5.000 & 4.875 \\
Second Flap & 8.250 & 7.875 \\
Second Edge & 20.000 & 19.374 \\
First Torsion & 25.875 & 25.250 \\
\hline
\end{tabular}

Amongst these modes was a coupled flap/edge mode near $17 \mathrm{~Hz}$ for both blades. The resolution of the frequency measurement was $0.125 \mathrm{~Hz}$.

\section{Damping}

The laboratories were also required to determine the damping for the first flap and edge modes. NREL used the $\log$ decrement method and measured the time constant of a decaying strain gage signal. NREL suspended $41 \mathrm{~kg}$ at $96 \%$ span and released it by cutting tie straps. The signal from the strain gage bending bridge at the root was recorded with an oscilloscope with a digitizing function. This measurement was made with the tip chord horizontal for the flap measurement, and vertical for the edge measurement. The critical damping coefficient was determined by fitting a damped sine wave to the data, using a nonlinear regression program NLREG. ${ }^{3}$ The damping is unit-less and is determined by fitting the following equation to the data ${ }^{4}$ :

$$
x(t)=A e^{-\zeta \omega_{n} t} \sin \left(\omega_{d} t-\phi\right),
$$

where:

$$
\begin{array}{ll}
\mathrm{x}(\mathrm{t}) & =\text { the signal value at time } \mathrm{t} \\
\mathrm{A} & =\text { the undamped amplitude } \\
\zeta & =\text { the damping factor } \\
\omega_{\mathrm{n}} & =\text { the undamped natural frequency } \\
\phi & =\text { the phase angle }
\end{array}
$$

and,

$$
\omega_{d}=\omega_{n} \sqrt{1-\zeta^{2}}
$$

where the difference between $\omega_{\mathrm{d}}$ and $\omega_{\mathrm{n}}$ is a small quantity of second order.

The curve fit was used to solve for the damping, $\zeta$.

Table 3 - Damping Results

\begin{tabular}{lcc}
\hline Mode & $\begin{array}{c}\text { Blade \#66 } \\
\text { Damping }\end{array}$ & $\begin{array}{c}\text { Blade \#67 } \\
\text { Damping }\end{array}$ \\
\hline First Flap & $0.0038 \pm 0.0004$ & $0.0044 \pm 0.0004$ \\
First Edge & $0.0042 \pm 0.0002$ & $0.0037 \pm 0.0001$ \\
\hline
\end{tabular}

Because the energy released in the step relaxation contains all frequencies, all modes are excited in the blade. This creates a noisy signal that reduces the accuracy (error of $10 \%$ for the flap) of the curve fit. A better approach would be to excite the blade at the first mode with an electrodynamic shaker and then remove the excitation and record the decaying signal.

\section{STATIC TESTS}

Static tests were performed prior to the fatigue tests. The project laboratories agreed on common load magnitudes and a spanwise application location to perform strain verification tests on the blade. Several strain gage measurement locations were also prescribed. Additional measurement locations were chosen by NREL. A total of 36 strain measurements and 2 bending bridges were used for each blade. Gages were placed at 5 blade span locations including the root. Gages were placed at mid-panel fore and aft of the blade spar and along the spar. Three-axis rectangular rosette gages were used on the compressive side midpanels. The SMT project prescribed measurement of blade displacements at the load application point and at the tip for each blade test.

Static test loads were taken from the NedWind 25 design extreme load cases. The flap load was for the parked extreme wind speed condition of $52.2 \mathrm{~m} / \mathrm{s}$. The edge load was for a utility grid short circuit at a wind speed of $20 \mathrm{~m} / \mathrm{s}$. To determine the design loading, the extreme loads were multiplied by a design load factor of 1.5 . The mandatory test load was taken to be $75 \%$ of this value. The load application point was at the $7.65 \mathrm{~m}$ spanwise location for both flap and edge loading to correspond with the same point used in an earlier NedWind static test in 1992. 
After recording data for the SMT program load $(75 \%$ extreme loads), NREL decided to increase the load to $110 \%$ of the extreme loads because NREL's damage equivalent fatigue test loads were near the extreme loads. Therefore it was necessary to verify that the blade strains would maintain linearity throughout the load range where NREL would be testing.

NREL constructed a blade saddle for the load application, which allowed the load to be uniformly distributed over the blade chord. For the edge static test, we applied the load with an overhead crane. The crane was operated with hand-controlled hydraulics and a digital load readout that the crane operator could read. For the flap static test an MTS actuator with an MTS T/RAC digital control system was used to apply the load with a ramp-and-hold command signal. We applied the loads in both cases by going to the SMT prescribed load ( $75 \%$ extreme), next was $100 \%$ of the extreme load, and then to $110 \%$ of the extreme load. Some audible cracking sounds were heard during the loading but we judged them to be typical for a static strength load test on a fiberglass blade and did not believe that they were an indication of permanent damage.

The strain gage signals and the applied load were recorded using NREL's BSTRAIN software. ${ }^{5}$ The actuator displacement was also recorded for the flap test. For the edge test, the load application displacement was measured with a string potentiometer. The tip displacements for edge and flap tests were recorded manually from linear retractable scales. The deflection data at the SMT prescribed load is presented in Table 4.

Table 4 - Static Blade Deflections

\begin{tabular}{lcccc}
\hline $\begin{array}{l}\text { Blade/ } \\
\text { Loading }\end{array}$ & $\begin{array}{c}\text { \#66 } \\
\text { Edge }\end{array}$ & $\begin{array}{c}\# 67 \\
\text { Edge }\end{array}$ & $\begin{array}{c}\text { F66 } \\
\text { Flap }\end{array}$ & $\begin{array}{c}\# 67 \\
\text { Flap }\end{array}$ \\
\hline $\begin{array}{l}\text { Load Point } \\
\text { (mm) }\end{array}$ & $47 \pm 0.5$ & $48 \pm 0.5$ & $192 \pm 0.8$ & $192 \pm 0.8$ \\
$\begin{array}{l}\text { Tip } \\
(\mathbf{m m})\end{array}$ & $98 \pm 3$ & $101 \pm 3$ & $503 \pm 3$ & $503 \pm 3$ \\
\hline
\end{tabular}

The load point deflections were determined by using a linear regression of the actuator displacement data. The tip deflections were read off the scales at the maximum load, and the deflections at the prescribed loads were interpolated.
Figure 4 shows the strain gage signal 41S40UA, which had the highest strain in the flap loading case. Results from both static blade tests are shown. This gage is positioned at $41 \%$ span on the suction surface at the $40 \%$ chord spar location. The data shows a $5 \%$ difference at the upper end of the loading sequence. This difference could be because of the variability in the gage placement, blade manufacturing, or measurement accuracy.

An indication of imminent buckling is non-linear behavior in the strain gage signals. ${ }^{5}$ The figure shows linear behavior at all loads, which was typical for all the longitudinally aligned gages. We concluded that no structural failure or buckling stability limits were reached during the static tests. This result was also important because the peak fatigue test loads approached the magnitude of these static test loads and it was necessary to verify that the fatigue tests were within the linear range.

\section{FATIGUE TESTS}

The methodology for conducting fatigue testing of wind turbine blades is inherently more complex than for static testing. The extreme static loads can usually be applied to the blade at near face value with some certainty, but the fatigue load spectrum must first be compressed and simplified, then applied to the blade within the constraints of the laboratory's hardware. As a result, fatigue-testing methodology has more permutations among the laboratories and is less easily defined by a simple procedure. The SMT partners agreed that the "business as usual" practices for each laboratory should be followed to allow a wider range of methods to be examined.

\section{Test Load Factors}

To minimize the variability among the laboratories the project laboratories agreed to use the same interpretations for the load factors when scaling the design spectrum. In addition, NREL agreed to adhere to the prescriptive portions of IEC 61400-23. In particular, the following test load factors were applied by all the laboratoriess to the design loads, in addition to the factors applied by NedWind in the design. 


\section{Table 5 - Fatigue Test Load Factors Used}

\begin{tabular}{ll}
\hline Test Load Factors & Value \\
\hline Wind Farm Turbulence & 1.04 \\
Blade to Blade Variations & 1.10 \\
Fatigue Formulation Uncertainty & 1.05 \\
\hline
\end{tabular}

Previous fatigue tests performed at NREL have used the following methods:

1. Separate (sequential) fatigue tests of the flap and edge directions.

2. Combine flap and edge fatigue test with blade pitched to a prescribed angle for the proper resultant load.

3. Conduct two-axis test with separate flap and edge load inputs.

NREL decided to conduct a single-axis test and a twoaxis test on our blades to compare the methods 2 and 3 . Although method 2 is simpler to implement, it is a poorer representation of the true operating condition.

\section{SINGLE-AXIS FATIGUE TEST BLADE \#67}

The single-axis test is the simplest and fastest of the fatigue test methods used at NREL. It requires a single actuator for testing both flap and edge directions at the same time. The disadvantages are the greater inaccuracy in matching the blade damage of the test to the theoretical design blade damage. Single-axis loading requires the two load components to be applied in-phase at a fixed load angle. This causes a resultant load that can exceed the design damage at certain locations around the blade section, while at other chordwise positions the blade may be under-tested. Single-axis testing also requires that the flap and edge loading be applied at the same load amplitude ratio $(R$ ratio), which prevents the flap and edge loads from being optimized for the design spectrum. ${ }^{6}$

\section{$\underline{\text { Single-Axis Fatigue Test Loads }}$}

The test loads were developed by matching the damage caused by the 20-year design load spectrum to the damage resulting for the test load for the composite material $\mathrm{S}-\mathrm{N}$ slope of $\mathrm{m}=10$. NREL chose to reduce the design spectrum to 3 million constant amplitude cycles at a load amplitude ratio of -0.1 , for an approximate test duration of 1 to 3 months. Since the single axis test requires that both load components be applied at the same load amplitude ratio, the -0.1 load amplitude ratio was a compromise between the optimum edge and flap ratios. More details of this procedure are given in Reference 7.

Figure 5 shows a photo of the single-axis fatigue test in operation. The load actuator was aligned such that the resultant load went through the elastic center of the chord, assumed at $40 \%$ in order to minimize the introduction of torsional moments.

\section{$\underline{\text { Single-Axis Fatigue Test Results }}$}

There was initial concern that the high resultant forces from the combined in-phase loading might cause buckling in the suction side leading edge panel. However, NREL became comfortable within the first few thousand cycles since no non-linear behavior was observed.

NREL also fixed the test frequency during this initial period. At $1.5 \mathrm{~Hz}$ the controller was having trouble keeping up with the command signal because the blade tip had developed its own independent vibration mode. Also, we were concerned about the possibility of the blade tip hitting the relatively low ceiling if an unstable control anomaly were encountered. We decided to cut off the outer two meters of the blade to remedy these concerns. With the tip removed, we were able to attain $1.5 \mathrm{~Hz}$ with stable control.

NREL observed two areas of blade damage during the test. The first was a crack that developed at the polyurethane joint interface at the root flange assembly. The crack eventually propagated around the root circular section. Although this crack did not appear to have immediate structural significance, it would allow moisture intrusion in the field. The second damaged area was a crack inboard of the maximum chord on the trailing edge. This was in the portion of the span where the blade transitions from an airfoil to a circular root section. The crack began at approximately 20,000 cycles and became very audible, as it grew to about $100-\mathrm{mm}$ in length. After that, the crack did not noticeably grow during the remainder of the test. The second crack seemed to develop locally as the curved airfoil section attempted to straighten under load. Similar damage was reported by CRES during their fatigue test.

Bolt pretension on the radial root bolts was checked under a schedule prescribed by the SMT project, using a torque wrench. Slight loosening was noted on one bolt (out of 21 ) at $2 \%$ and $20 \%$ test period checks. This bolt was located on the suction side by the trailing edge. 
Figure 6 shows the longitudinal strain gage signal 25S26UA-peak/valley levels over the duration of the test. This gage was located on the compressive surface at $25 \%$ span and $26 \%$ chord. This signal is a reduction of 6 million points taken over the test period. Nonpeak/valley data was removed around automatic stiffness checks and during startups and shutdowns. The peaks and valleys were separately averaged and decimated every 300 points. The first 100,000 cycles were not plotted because of a gage soldering failure. This figure is representative of most channels where the strain level during the test remained relatively constant.

Some strain gage channels failed during the test. In all cases, the replacement gage failed again. NREL concluded this was due to locally high strains in the laminate and not a fatigue failure of the gage caused by high blade strains. No visible signs of damage could be seen on the blade at these gage locations.

Figure 7 shows the global stiffness of the blade over the test period. The global blade stiffness can be an indication of blade failure. As much as a $10 \%$ loss in stiffness has been observed in previous tests prior to failure. $^{5}$ No significant change in test stiffness was noted during the test.

\section{$\underline{\text { Acoustic Emissions }}$}

A parallel acoustic emission test was conducted during the SMT static testing and single-axis fatigue testing by Sandia National Laboratories (SNL). ${ }^{8}$ Although this is not standard practice at NREL, SNL is often invited to join tests if it is of mutual benefit to the laboratories and the blade client. Sensors placed along the blade measured high frequency emissions that may be related to incipient blade damage during the test. SNL will provide a complete write-up of these results later. Preliminary results indicated high emissions around the observed root cracking and along the spar between station 2500 and 4200 on the compressive surface. The trailing edge crack was not detected because the sensors were not properly positioned to detect this damage. The spar damage will be verified during post-mortem sectioning.

\section{TWO-AXIS FATIGUE TEST BLADE \#66}

NREL recently developed a two-axis testing capability. Figure 8 shows a line drawing of the test hardware. Although this is a more complicated test method, it is faster than testing edge and flap separately, and similar in required time to a single-axis combined load test. The test damage is more realistic to the design load spectrum, because the load ratio (minimum/maximum) can be controlled separately for each axis. Also, the phase angle between flap and edge loads can be prescribed.

\section{$\underline{\text { Two-Axis Fatigue Test Loads }}$}

NREL developed a new method for computing the design equivalent loading from the load spectrum. The method optimizes the test load ratio by reducing the sensitivity in the damage to a bounded range of S-N curve slopes and bending moments. A phase angle of $90^{\circ}$ (flap leading edge) was chosen, which matches the phase in the design load time series. The number of cycles was fixed at 3 million, and the flap and edge load amplitude ratios were fixed at 0.10 and -0.40 , respectively. Reference 6 describes the effort to develop the two-axis test equipment at NREL. A full report of the test load development for the SMT program two axis testing is given in Reference 7.

\section{$\underline{\text { Two-Axis Results }}$}

NREL ran the two-axis test at $1.25 \mathrm{~Hz}$. Above this frequency it was more difficult to maintain continuous smooth loading. The trailing edge crack noticed in the single-axis test was first observed in the two-axis test between 420,000 and 440,000 cycles. This is more than one order of magnitude beyond the cycle count when it was first observed on the single-axis test. Note that for an S-N curve slope of 10 , a $10 \%$ reduction in stress results in an order of magnitude increase in allowable cycles. ${ }^{9}$

At 824,307 cycles NREL discovered that the load phasing was incorrect, with edge leading (instead of lagging) flap by $90^{\circ}$. This was corrected immediately. It will be difficult to completely assess the impact this error may have had on NREL's results; however the strain gage (peak/valley) responses showed little change when the phase angle was corrected. Therefore, NREL did not feel that the final results were greatly affected.

The same polyurethane root bond crack described for the single-axis test was also fully developed during the two-axis test. No loss of radial bolt torque was observed during scheduled checks.

Figure 9 shows the signal data from the same strain gage location in the two-axis test as Figure 6 did for the single-axis test. Although the signal valleys are approximately the same level, the single-axis data 
(Figure 6) had a higher strain amplitude and a reversing component. Some of the two-axis signals showed higher strain amplitude compared to the corresponding single-axis signal. These amplitude differences can be attributed to the different load ratios used between the single-axis test and the two-axis test that were needed to achieve the same damage.

No strain gage failures occurred during the two-axis fatigue test. Also, no loss of blade stiffness was observed in the two-axis test, which is the same result as the single-axis test.

\section{CONCLUSIONS AND RECOMMENDATIONS}

Two NedWind 25 blades manufactured by Rotorline were tested at NREL between August 1998 and May 1999. Static and fatigue tests were performed under the SMT Program. The program was very successful in helping NREL develop and demonstrate its methods for blade testing.

Results showed a high degree of correlation between the two blade static tests, which included eigenfrequencies, damping, displacements, and representative strain.

Two fatigue loading methods were used. The first blade was tested under single-axis loading and the second was tested under two-axis loading. The same damage was observed on both blades, but the onset of visible damage occurred sooner for the single-axis test. This corresponded to higher strains for the single-axis test at some gages locations.

Two-axis testing provides a better representation of the theoretical damage than single axis tests but it is not yet understood if this translates to better representation of actual field failures. However, the results of this testing suggest that for the NedWind 25 blade the single-axis test was conservative because the same damage was found earlier.

The NedWind 25 turbine operators should look for the same failures as observed in NREL's fatigue tests. For comparison, the trailing edge damage was observed at $14 \%$ into the lifetime. This corresponds to 2.8 years of a 20 -year design lifetime. Field failure reports have not been explicitly disseminated to the project laboratories for evaluation, but a follow-on inspection of the operating NedWind blades is recommended.

\section{ACKNOWLEDGEMENTS}

The authors wish to thank the large number of active contributors who made this project happen successfully. Thanks especially to the NREL Structural Test Team of Scott Hughes, Mike Jenks, Darren Deshay, Rich Osgood, Toby Stensland, Todd Longacre, Doug Cook and Ben Bourne. Thanks to Gregg Freebury, Mike Zuteck, and Jim Richmond for their special skills and insights in helping to develop the test loads. Thanks to Al Beattie and Mark Rumsey at Sandia National Laboratories for enhancing the testing with their acoustic emission monitoring. Thanks to our colleagues and friends in Europe at RIS $\varnothing$, CRES, Delft, and ECN for inviting us to join the project and accepting our input throughout the project. And finally, thanks to DOE for their continued funding support and recognition of Structural Testing as a valued asset of the wind energy industry.

\section{REFERENCES}

1. International Electrotechnical Commission 88/102/CD. Draft IEC 61400-22: Wind Turbine Certification. December 1998.

2. International Electrotechnical Commission 88/84/CD. Draft IEC 61400-23: Testing of Rotor Blades. September 1998.

3. NLREG Nonlinear Regression Analysis Program ver. 4.1, Sherrod Software, Brentwood, Tennessee.

4. Thomson, W.T. "Vibration." Chapter 5 in Mark's Standard Handbook for Mechanical Engineers. Eighth Edition. New York: McGraw Hill, 1978; p. 5-67.

5. Musial, W. D.; Clark, M. E.; Stensland, T. "Application of BSTRAIN Software for Wind Turbine Blade Testing." NREL/TP-440-21507. Windpower '96 Proceedings; June 23-27, 1996; Denver, Colorado. Washington D.C.: American Wind Energy Association; pp. 241-250.

6. Hughes, S.; Musial, W.; And Stensland, T. "Implementation of A Two-Axis Servo-Hydraulic System for Full-Scale Fatigue Testing of Wind Turbine Blades." NREL/CP-500-26896. Windpower 99 Proceedings; June 20-23, 1999, Burlington, Vermont. Washington D.C.: American Wind Energy Association. To be published.

7. Freebury, G.; Musial, W.; Larwood, S. "Determining Equivalent Damage Loading for Full-Scale Wind Turbine Blade Fatigue Tests." AIAA-2000-0050. 38 th AIAA Aerospace Sciences Meeting and ASME Wind Energy Symposium; January 10-13, 2000; Reno, Nevada. Reston, Virginia: American Institute of Aeronautics and Astronautics. To be published. 
8. Beattie, A.G. "Acoustic Emission Monitoring of a Wind Turbine Blade During a Fatigue Test." AIAA-97-0958. $35^{\text {th }}$ AIAA Aerospace Sciences Meeting and ASME Wind Energy Symposium; January 6-9, 1997; Reno, Nevada. Reston, Virginia: American Institute of Aeronautics and Astronautics.

9. Mandell, J. F. "Fatigue Behavior of Short Fiber Composite Materials." Chapter 7 Fatigue of Composite Materials. Reifsnides, K. L., ed. New York: Elsevier Science, 1991; pp. 232.

\section{FIGURES}

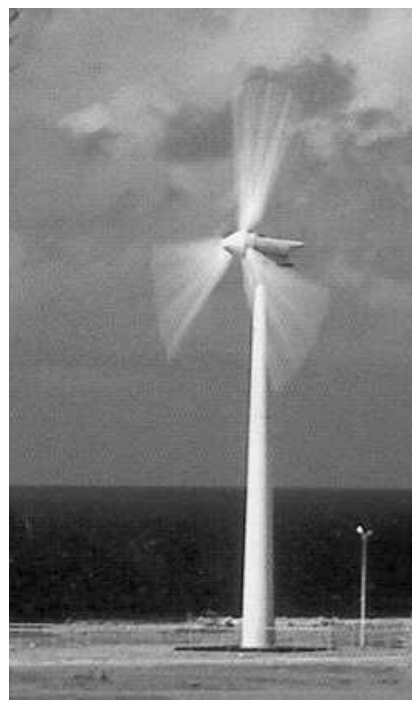

Figure 1. NedWind 25 in Curaçao (photo courtesy of Paul Gipe)

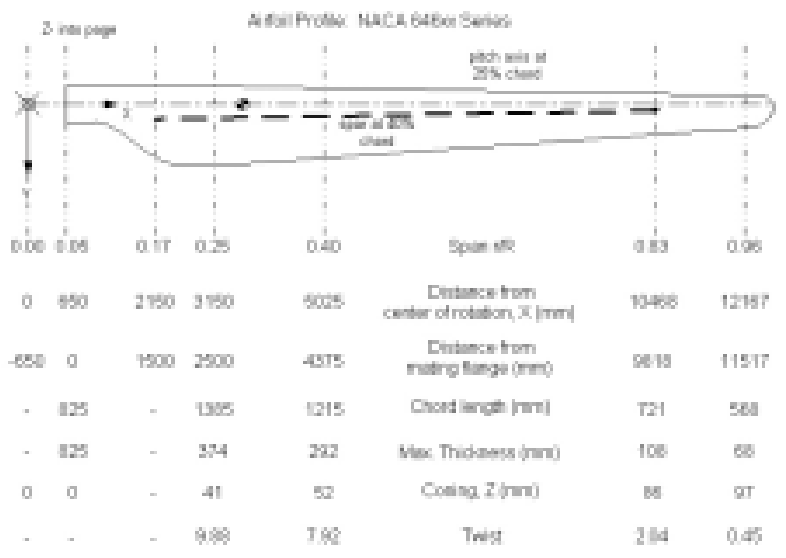

Figure 2. NedWind 25 Blade Planform

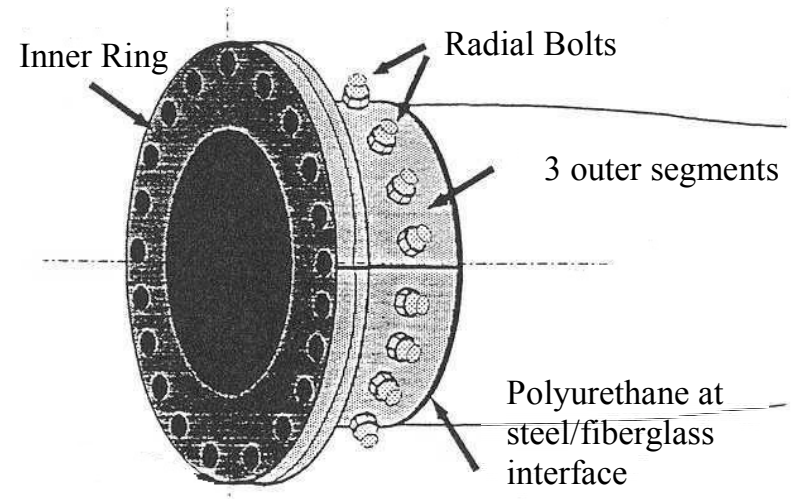

Figure 3. Blade root detail

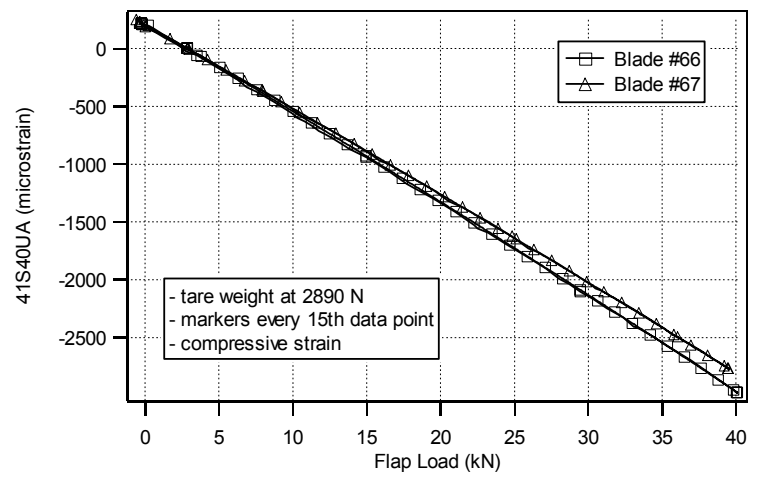

Figure 4. Strain versus load for 41S40UA, static flap loading with gage at $41 \%$ span, $40 \%$ chord in longitudinal direction. 


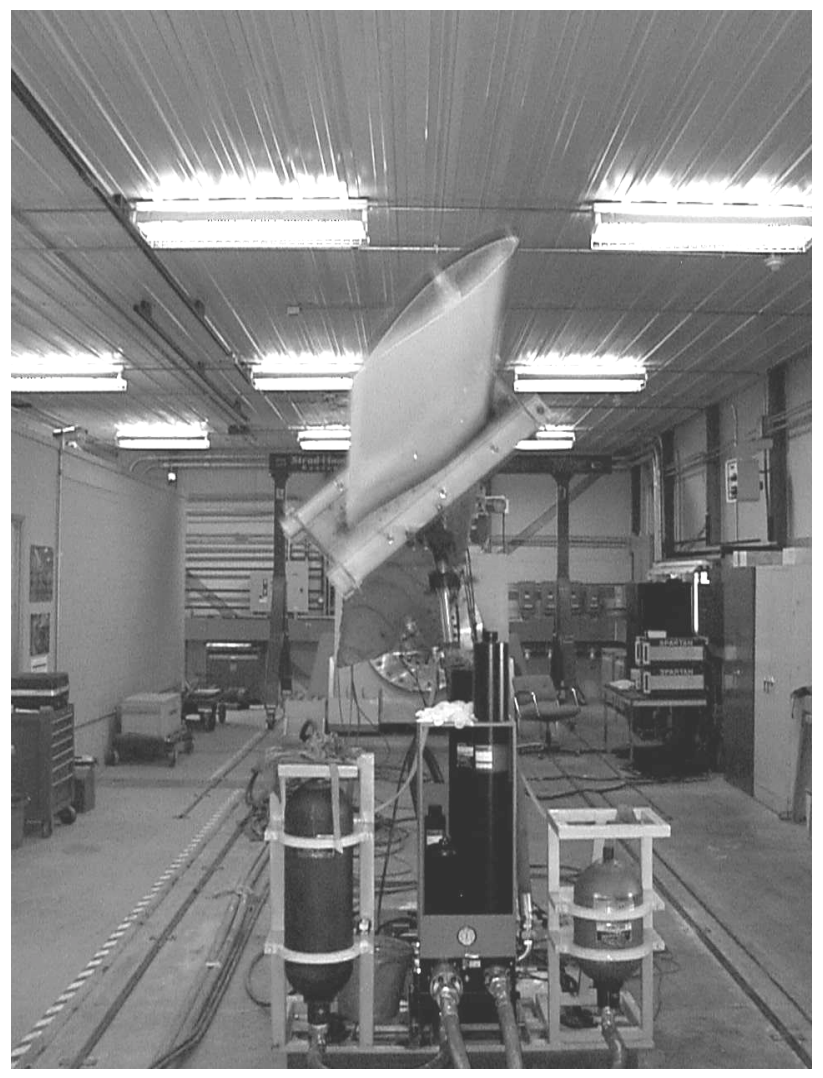

Figure 5. Single-Axis fatigue test in operation

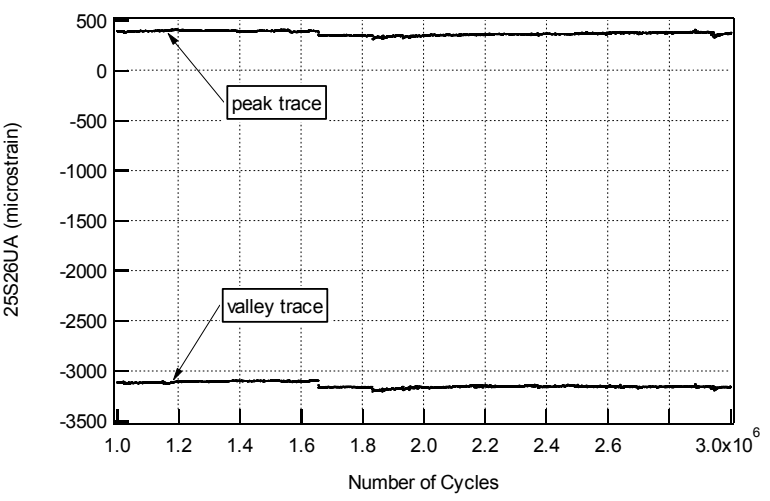

Figure 6. 0-degree strain versus cycle number for gage 25S26UA, blade \#67 single-axis fatigue test. $25 \%$ span, $26 \%$ chord on compressive surface.

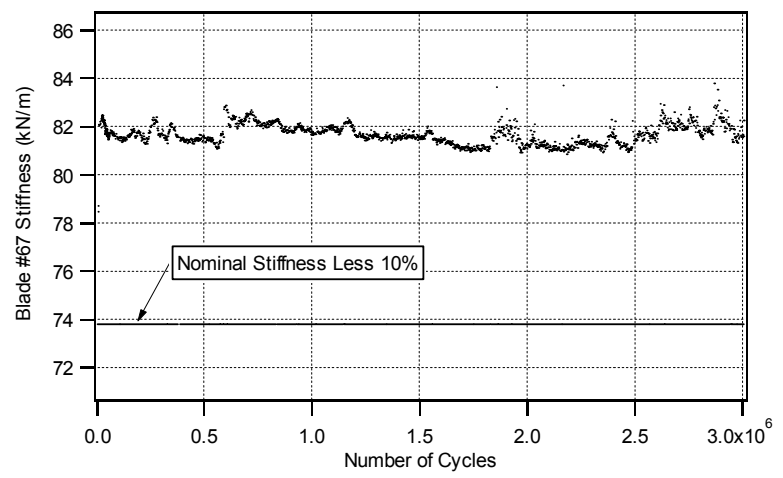

Figure 7. Blade \#67 stiffness, single-axis fatigue test

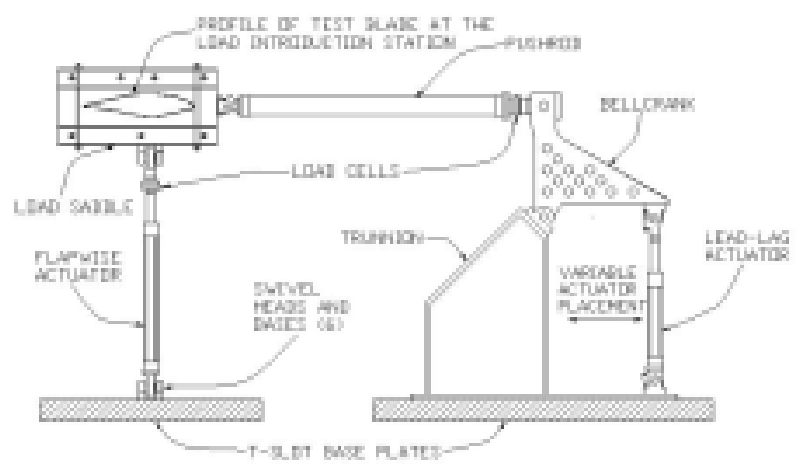

Figure 8. Two-axis fatigue test setup

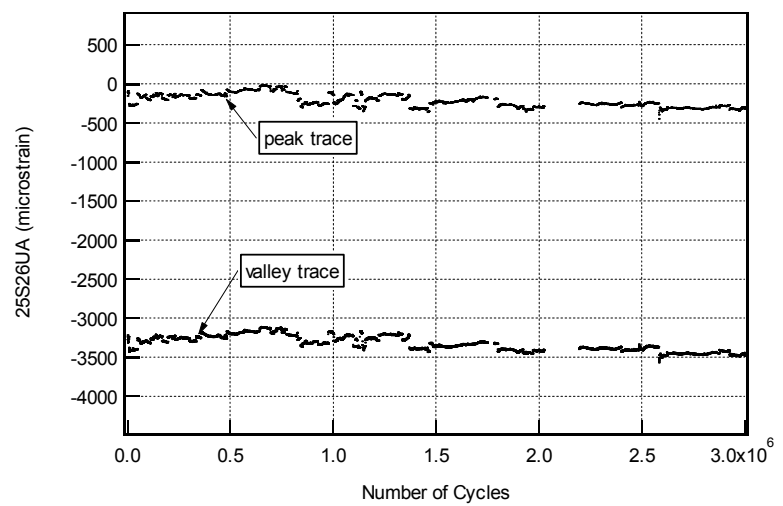

Figure 9. 0-degree strain versus cycle number for gage 25S26UA, blade \#66 two-axis fatigue test. $25 \%$ span, $26 \%$ chord on compressive surface. 